\title{
Derroteros fundamentales de la cuestión de los principios en el pensamiento jurídico occidental del siglo $X X$
}

Fundamental courses of the question of principles in western legal thought of the 20th century

Derroteros fundamentais da questão dos princípios no pensamento jurídico ocidental do século $\mathrm{XX}$

Chemins fondamentales de la question des principes dans la pensée juridique occidentale du XXe siècle

二十世纪西方法律思想中原则问题的基本走向

\author{
Alejandro González Monzón ${ }^{1}$ \\ Universidad de La Habana - Cuba
}

Revista Derechos en Acción ISSN 2525-1678/ e-ISSN 2525-1686

Año 5/No 16 Invierno 2020 (21 junio a 20 septiembre), 291-332

https://doi.org/10.24215/25251678e425

Recibido: 01/06/2020

Aprobado: 01/07/2020

Resumen: El presente trabajo tiene como objetivo presentar los derroteros fundamentales que ha asumido la cuestión de los principios en el pensamiento jurídico occidental del siglo XX. En este sentido, se identifican y desarrollan en sus aspectos esenciales cinco tendencias sobre

\footnotetext{
1 Licenciado en Derecho por la Universidad de La Habana (2017). Profesor de Filosofía del Derecho y Derecho Romano de la Facultad de Derecho de la Universidad de La Habana. Profesor de la Escuela de Formación Judicial del Tribunal Supremo Popular de la República de Cuba. Juez de la Sala Segunda de lo Civil y de lo Administrativo del Tribunal Provincial Popular de la Habana. alejandro.gonzalez@lex.uh.cu (ORCID: https://orcid.org/0000-00022612-7267).
} 
el tema, a saber: Ios principios desde el discurso ontológico-jurídico; los principios desde el discurso de la teoría de las normas jurídicas; los principios desde el discurso de la metodología de la aplicación del Derecho; los principios desde el discurso de la teoría de los derechos fundamentales; y los principios desde el discurso de la argumentación jurídica.

Palabras clave: principios, reglas, ponderación, derechos fundamentales, argumentación.

\begin{abstract}
The objective of this work is to present the fundamental paths that the question of principles has assumed in western legal thought in the 20th century. In this sense, five trends on the subject are identified and developed in their essential aspects, namely: the principles from the ontological-legal discourse; the principles from the discourse of the theory of legal norms; the principles from the discourse of the methodology of the application of the Law; the principles from the discourse of the theory of fundamental rights; and the principles from the discourse of legal argumentation.
\end{abstract}

Keywords: principles, rules, weighting, fundamental rights, argumentation.

Resumo: 0 presente trabalho tem como objetivo apresentar os derroteros fundamentais que assumiu a questão dos princípios no pensamento jurídico ocidental no século XX. Neste sentido, são identificadas e desenvolvidas em seus aspectos essenciais cinco tendências sobre o tema, a saber: os princípios desde o discurso ontológico-jurídico; os princípios desde 0 discurso da teoria das normas jurídicas; os princípios desde 0 discurso da metodologia da aplicação do direito; os princípios desde 0 discurso da teoria dos direitos fundamentais; e os princípios desde 0 discurso da argumentação jurídica.

Palavras-chave: princípios, regras, ponderação, direitos fundamentais, argumentação.

Résumé: Le présent article vise à présenter les voies fondamentales empruntées par la question des principes dans la pensée juridique occidentale du XXe siècle. En ce sens, cinq tendances sur le sujet sont identifiées et développées dans leurs aspects essentiels, à savoir: les principes issus du discours ontologico-juridique; les principes issus du discours de la théorie des normes juridiques; les principes issus du discours sur la méthodologie de l'application de la loi; les principes issus du discours 
de la théorie des droits fondamentaux; et les principes du discours de l'argumentation juridique.

Mot-clés: principes, règles, pondération, droits fondamentaux, argumentation.

摘要：本工作旨在介绍二十世纪西方法律思想中原则问题所采取的 基本路径. 从这个意义上讲, 在主题的五个基本方面确定并发展了五 个趋势, 即: 本体论-法律话语的原理法律规范理论话语中的原则, 讨 论法律适用方法论的原则, 基本权利理论论述中的原则, 以及法律论 证中的原则

关键字: 原则, 规则, 权重, 基本权利, 论证

\section{Consideraciones preliminares sobre la dimensión principial del Derecho}

La dimensión principial del Derecho, esto es, la posibilidad de existencia de principios en las expresiones propias del fenómeno jurídico, ha tenido manifestaciones diferenciadas, remontándose la cuestión a los inicios de la reflexión iusfilosófica occidental, ${ }^{2}$ esto a pesar de que la expresión principios, aplicada específicamente al Derecho, tiene su asiento originario en la obra de LuL. ${ }^{3}$ La identificación definitoria de los principios y la demarcación de sus funciones, lejos de lo incidental, se pueden asumir como pilares epistémicos del conocimiento del Derecho. La ciencia jurídica, recordaba García de ENTERRía, no tiene otra misión que la de desvelar y descubrir a través de conexiones de sentido cada vez más profundas y ricas, mediante la construcción de instituciones y la integración respectiva de todas ellas en un conjuntó,

\footnotetext{
2 Cfr. Mans Puigarnau, J. M., Los principios generales del Derecho. Repertorio de reglas, máximas y aforismos jurídicos con la jurisprudencia del Tribunal Supremo de Justicia, Barcelona, Bosch, 1947, pp. V y ss; y Pattaro, E., “El origen de la noción principios generales del derecho. Lineamiento histórico-filosófico," en Boletín Mexicano de Derecho Comparado, México, año XIX, no. 59, 1987, pp. 525-563.

3 Cfr. LluLl, R., Arte de Derecho, Madrid, Universidad Carlos III, 2011, p. 58. Comentarios al respecto en De Castro y Bravo, F., Derecho Civil de España, tomo I, Madrid, Civitas, 1984, p. 417.
} 
los principios generales sobre los que se articula y debe, por consiguiente, expresarse el orden jurídico. ${ }^{4}$

Una apreciación global arroja la configuración de tres grandes perspectivas de análisis en las disertaciones teóricas sobre los principios en el Derecho, a saber: la perspectiva ontológica, ${ }^{5}$ es decir, la relativa a la conceptualización del Derecho; la perspectiva de identificación del sistema de fuentes formales del Derecho; ${ }^{6}$ y la perspectiva desarrollada en ocasión de la teoría de las normas jurídicas, ${ }^{7}$ con implicaciones en sus formas aplicativas y en las estructuras argumentativas correspondientes. A pesar de que estas perspectivas se yuxtaponen constantemente en los sistemas iusfilosóficos, es posible introducir criterios históricos de diferenciación que coadyuvan a la mejor comprensión de la reflexión principalista.

La perspectiva ontológica del discurso principalista tiene su origen en la sistematización iusnaturalista, cuya génesis se localiza en la especulación grecolatina, ${ }^{8}$ mientras que su ocaso,

4 García de Enterría, E., "Reflexiones sobre la ley y los principios generales del Derecho en el Derecho Administrativo," en Revista de Administración Pública, Madrid, Instituto de Estudios Políticos, no. 40, enero-abril de 1963, pp. 201-202.

5 Vid, entre otros, DeL Vecchio, G., Los principios generales del Derecho, Barcelona, Bosch, 1933, pp. 23-38; y Botero Bernal, A., "La jerarquía entre principios generales del Derecho: la historicidad y la culturalidad de principio de justicia," en Revista de Derecho, Barranquilla, Universidad del Norte, no. 23, 2005, pp. 29-68.

6 Vid, entre otros, De Ruggiero, R., Istituzioni di Diritto Civile, vol. I, Messina-Milano, Casa Editrice Giuseppe Principato, 1934, p. 56; Díaz Couselo, J., Los principios generales del derecho, Buenos Aires, Plus Ultra, 1971, p 83; Beladiez Roso, M., Los principios jurídicos, Madrid, Tecnos, 1994, p. 111; Díez-Picazo, L., y A. Guloón., Sistema de derecho civil, Madrid, Tecnos, 1997, p. 144; y Souella Narduccl, A., Introducción al estudio del derecho, Santiago de Chile, Editorial Jurídica, 2000, p. 271.

7 Cfr. Dworkin, R., “Es el Derecho un sistema de reglas?” en Filosofía del Derecho, México, Fondo de Cultura Económica, 1980, in integrum; Alexy, R., Teoría de los derechos fundamentales, Madrid, Centro de Estudios Constitucionales, 1993, pp. 81 y ss; Guastinı, R., Interpretar y argumentar, Madrid, Centro de Estudios Políticos y Constitucionales, 2014, pp. 183 y ss; y Atienza, M., y J. Ruiz Manero., Las piezas del Derecho. Teoría de los enunciados jurídicos, Barcelona, Ariel, 1996, pp. 6 y ss.

8 Cfr. Aristóteles., Metafísica, Madrid, Aguilar, 1973, pp. 121-122; y Cicerón., Tratado de República, México, Fondo de Cultura Económica, 1992, p. XXII. 
al menos en su vertiente clásica, aconteció como uno de los desprendimientos del sistema totalizador de Hegel, ${ }^{9}$ constituyendo momentos intermedios trascendentales en este íter evolutivo la apología teológica del derecho natural sucedida en el espacio medieval ${ }^{10}$ y la conjugación racionalista del Derecho de los siglos XVII y XVIII. ${ }^{11}$ En líneas generales, y dada la poca organicidad de los estudios teórico-jurídicos que se exhibe en este interregno histórico, los principios se comportaron como pautas de legitimación de la existencia de un orden de normatividad jurídica suprapositivo. Es decir, los principios se asumieron como un correlato del esquema iusnaturalista, entendiéndose su razón de existencia bien en las ideas platónicas, en la substancia aristotélica, en las manifestaciones de la moral, en la voluntad divina o en las exigencias de la razón.

En contraposición, la salida iuspositivista, que comenzó a sedimentarse a finales del siglo XIX, ha negado la existencia de un orden normativo trascedente a la realidad positivada y, por consiguiente, la virtualidad de principios que, contenidos en aquel, informen los procesos de creación, interpretación y aplicación del Derecho. Este contrapunteo entre el naturalismo y el positivismo jurídico, aunque con ropajes diferentes, se ha mantenido hasta la actualidad, y constituye la apoyatura iusfilosófica general de todas las discusiones relativas a los principios jurídicos. De manera muy especial, el debate en torno a la separación entre el Derecho y la moral es un punto de referencia de importancia vital, pues como se podrá analizar con más detenimiento, las cargas axiológicas son consustanciales al principalismo.

La perspectiva de identificación del sistema de fuentes formales del Derecho está definida por la negación del imperio

9 Cfr. Hegel, J. G. F., Filosofía del Derecho, Buenos Aires, Claridad, 1968, pp. 67 y ss.

10 Cfr. De Aouino, T., Suma de Teología, Madrid, Biblioteca de Autores Cristianos, 2001, pp. 866 y 948.

11 Vid, a modo de ejemplo, el racionalismo postulado en LeiBnIz, G. W., Tres ensayos: El Derecho y la equidad; la Justicia; y la Sabiduría, México, Centro de Estudios Filosóficos de la UNAM, 1960, p. 5. 
absoluto de la ley ${ }^{12}$ (defendido inicialmente por los exegetas franceses y contravenido por GÉNY $)^{13}$ y la referencia a los llamados principios generales (o naturales) del Derecho (o del ordenamiento jurídico); ${ }^{14}$ tiene su fundamento primario en la aspiración de materializar normativamente las tesis del iusnaturalismo y su despliegue originario coincide con los grandes procesos de codificación realizados a finales del siglo XVIII, durante todo el siglo XIX y en buena parte del siglo XX ${ }^{15}$ Los posicionamientos de inclusión de los principios como fuentes formales del Derecho responden a una toma de consciencia

12 Cfr. Rivero, J., “Los principios generales del Derecho en el Derecho Administrativo francés contemporáneo," en Revista de Administración Pública, Madrid, no. 6, año II, Instituto de Estudios Políticos, septiembre-diciembre de 1951, pp. 289-290.

13 Cfr. Gény, F., Método de interpretación y fuentes en Derecho Privado positivo, Madrid, Reus, 1925, pp. 2 y ss.

14 Respecto a la inclusión de los principios generales del Derecho en los sistemas de fuentes formales es posible identificar cuatro grandes modelos, estos son: a-) modelos no inclusivos: inspiradas en el modelo del Code napoleónico de 1804, las legislaciones contenidas en este modelo carecen de referencia a los principios generales del Derecho, adoptando una postura genérica de preponderancia de la ley que no permite la inclusión de fuentes subsidiarias; b-) modelos de interpretación reglada: las legislaciones que se insertan en este modelo tampoco establecen fuentes subsidiarias de forma directa, no obstante, consagran pautas interpretativas que dan al traste con la posibilidad de utilizar el recurso analógico y la aplicación de los principios generales del Derecho a fin de salvar contradicciones y vacíos en el ordenamiento jurídico; c-) modelos de remisión: tiene como característica que las legislaciones en él comprendidas introducen fuentes subsidiarias, aunque diferenciadas de los principios generales del Derecho; y d-) modelos de inclusión: con un antecedente remoto en la codificación austriaca, las legislaciones incluidas en este modelo incluyen a los principios generales del Derecho en el sistema de fuentes formales que consagran.

15 Son hitos trascendentales en este sentido, por solo citar los más representativo: el artículo 19 del Código civil austriaco de 1797 (que informó la redacción del artículo 7 del Código de igual nacionalidad promulgado en 1811); el artículo 15 del Código civil Albertino de 1837; el artículo 3, párrafo 2, del Codice civile de 1865; el artículo 6, apartado 2, del Código civil español de 1888; y el artículo 12 del Codice civile de 1942, que significó un giro hacia el positivismo al sustituir la expresión principi generali del Diritto por la de principi generali dell'ordinamento giuridico. En el caso del Code de 1804 y del BGB, se hace notar la ausencia de remisión a los principios generales del Derecho. En ambos casos, la aplicación de los principios se pude colegir de la concurrencia de lagunas en el caso controvertido y de la obligación de los jueces de emitir resoluciones fundadas en Derecho respecto de las cuestiones planteadas (prohibición de non liquet), así como de la aplicación analógica, que conlleva la extracción de los principios generales. 
sobre la imposibilidad de un ordenamiento jurídico exhaustivo, ${ }^{16}$ es decir, sin lagunas, vaguedades o contradicciones, integrado solamente por normas explícitas con hipótesis meridianamente definidas.

La perspectiva desarrollada en ocasión de la teoría de las normas jurídicas tiene su espacio natural en el siglo XX $\mathrm{y}$ es expresiva de un grado superior de perfeccionamiento $\mathrm{y}$ organicidad en los estudios teóricos sobre el Derecho desde un prisma analítico. Evidentemente, esta línea de análisis presupone posicionamientos específicos respecto a las perspectivas anteriores, a saber, la posibilidad de no concebir al Derecho como una declaración exclusiva de la voluntad del Estado y la aceptación de lo imperioso de establecer un sistema de fuentes formales que posibilite una solución coherente y racional ante la concurrencia de una insuficiencia regulativa de la ley y, en su caso, de la costumbre aplicable al caso. No obstante, desde la teoría de las normas jurídicas el asunto de los principios se ha redimensionado, pues a su tenor ha dejado de ser parte de un discurso preponderantemente metafísico para integrar una serie de problemáticas que, desde un sentido más pragmático y operativo, trascienden a la metodología de la regulación jurídica, a las técnicas de aplicación del Derecho y los ejercicios de argumentación en estas lides. ${ }^{17}$

\footnotetext{
16 Sobre la tesis de la plenitud del ordenamiento jurídico vid Romano, S., El ordenamiento jurídico, Madrid, Instituto de Estudios Políticos, 1963, pp. 316-317; Zitelmann, E., “Las lagunas del Derecho," en Savigny, Kirchmann, Zitelmann, Kantorowicz, La Ciencia del Derecho, Buenos Aires, Losada, 1989, in integrum; Donatı, D., Il problema delle lacune dell'ordinamento giuridico, Milano, Società Editrice Libraria, 1910, pp. 28-56 y 126 y ss; y KelSEN, H., El método y los conceptos fundamentales de la teoría pura del derecho, Madrid, Revista de Derecho Privado, 1933, pp. 65-66.

17 Esta idea es concordante con lo expresado por García de EnTERRía, para quien el enfrentamiento al positivismo legalista condujo al pensamiento jurídico occidental a una concepción sustancialista y no formal del Derecho, "(...) cuyo punto de penetración, más que en una metafísica de la justicia, en una axiomática de la materia legal, se ha encontrado en los principios generales del Derecho, expresión (...) susceptible (...) de una seguridad de funcionamiento y de manejo que se volatilizaría si el tradicional lugar de la ley pretendiese ser sustituido por una abstracta e indeterminada invocación de la justicia, o de la conciencia moral o de la discreción del juez (... .)." García de Enterría, E., "Reflexiones...," op. cit., pp. 199-200.
} 


\section{El siglo XX y el auge principalista: sistematización sus tendencias fundamentales}

En sentido general, y como ha quedado ilustrado hasta el momento, la teoría sobre los principios jurídicos ${ }^{18}$ es el reflejo de la dinámica evolutiva de una reflexión teórica sobre el Derecho que, en su génesis, intenta combatir las tesis fundamentales del iuspositivismo. ${ }^{19} \mathrm{El}$ modelo anti-iuspositivista, que tiene como noción central la pertenencia de los principios al Derecho, diluye, como acotó CARrió, la distinción entre fuentes formales y materiales, ${ }^{20}$ pues lo vincula continuamente a factores sociales, especialmente de naturaleza moral. Si bien no es posible desconocer los correlatos principalistas del iusnaturalismo clásico y sus derivaciones, es lo cierto que esta cuestión alcanzó la delineación de sus contornos más trascendentales en la teoría del Derecho contemporánea, entendiendo como tal a la que se comenzó a construir desde los inicios del siglo $\mathrm{XX}$ y que al día de hoy marca no pocos de los esquemas sobre los que discurren los estudios teóricos y metateóricos sobre el fenómeno jurídico y sus diversas manifestaciones.

Autores como Atienza y Ruiz Manero, que obviamente comparten este criterio, señalan el punto de arranque del giro contemporáneo de la discusión acerca de los principios jurídicos en los cuestionamientos realizados por Dworkin al iuspositivismo de HART ${ }^{21}$ cuyo epicentro, como especificó WaLDron, es una concepción sobre lo que supone el Derecho aparte de una multitud de reglas formales. ${ }^{22}$ Obviamente, este giro contemporáneo

\footnotetext{
18 Una recreación sistemática en De FAzıo, F., "La teoría de los principios. Un estado de la cuestión," en Lecciones y Ensayos, Buenos Aires, no. 100, 2018, pp. 43-68.

19 Vid, entre otros, Cianciardo, J., "Principios y reglas: una aproximación desde los criterios de distinción," en Boletín Mexicano de Derecho Comparado, México, no. 108, año XXXVI, septiembre-diciembre de 2003, pp. 891-906.

20 Apud Carrió, G., Notas sobre Derecho y lenguaje, Buenos Aires, Abeledo-Perrot, 1986, p. 223.

21 Cfr. Atienza, M., y J. Ruiz Manero., Las piezas..., op. cit., p. 1.

22 Cfr. Waldron, J., “ ¿Ha respondido Dworkin a los Estudios Críticos del Derecho?” en Melero de LA Torre, M. C., et. al., Dworkin y sus críticos. El debate sobre el imperio de la Ley, Valencia,
} 
alude a una reactualización del protagonismo de los principios en los debates teóricos, ${ }^{23}$ y no al surgimiento de la polémica, que como ya se puntualizó hunde sus raíces en los orígenes de la especulación iusfilosófica.

Incluso, en los propios marcos de los novecientos, es plausible entender que este punto de arranque puede ser retrotraído a los enfrentamientos inmediatos que suscitó la teoría pura del Derecho de Kelsen. ${ }^{24}$ En efecto, la teoría sindicada por KelSen, basada en estrictos criterios de selección normativa como presupuesto para la armonía y completitud del ordenamiento ${ }^{25}$ y renuente a la incorporación de estandarizaciones morales en lo jurídico, abrió una estela de controversias que todavía en la actualidad tienen resonancia. Particularmente, debe destacarse el posicionamiento de Esser, para quien la praxis jurídica en términos kelsenianos resultó caricaturesca, y cuyos errores generaron una catalización del significado de los principios en la aplicación del Derecho. ${ }^{26}$ Los principios, en el pensamiento esseriano, no se conciben como provenientes de un orden

Tirant lo Blanch, p. 265. También vid Soper, E. P., “Legal Theory and the Obligation of a Judge: The Hart-Dworkin Dispute," en Michigan Law Review, Lansing, vol. 75, 1977, pp. 473-519.

23 Apud Pérez Luño, A. E., "Los principios generales del Derecho: ¿un mito jurídico?" en Revista de Estudios Políticos, Madrid, nueva época, no. 98, octubre-diciembre de 1997, p. 12.

24 Es importante recordar que KeLSEN no atribuyó a los principios la condición de normas jurídicas. Este posicionamiento lo manifestó claramente en su teoría al sostener que “(...) tales principios no tienen carácter de normas jurídicas. Si no se separa claramente el concepto de norma jurídica y el concepto de principio jurídico, entonces se borra el límite entre el derecho positivo, por un lado, y, por otro, la moral, la política y las costumbres, lo cual solo puede ser deseable para tales representantes de la ciencia del derecho, que creen que su tarea consiste no tanto en conocer el derecho positivo y describirlo objetivamente, sino más bien en justificar o cuestionar su validez desde el punto de vista de la moral y la política (...)." Kelsen, H., Teoría general de las normas, México, Trillas, 1994, p. 125.

25 Sobre este tópico vid las fundamentadas observaciones de WALTER, R., La estructura del orden jurídico. Disertación jurídico-teórica basada en la teoría pura del derecho, Bogotá, Temis, 1984, pp. 11 y ss.

26 Cfr. Esser, J., Principio y Norma en la elaboración jurisprudencial del Derecho Privado, Barcelona, Bosch, 1961, pp. 169-171. También vid Ramos Pascua, J. A., "El fundamento del vigor jurídico de los principios. Dworkin frente a Esser," en Anuario de Filosofía del Derecho, Madrid, tomo IX, Ministerio de Justicia, 1992, pp. 278 y ss. 
universal a la usanza iusnaturalista, ni como meras inducciones de las normas existentes en forma cerrada tal y como han postulado los iuspositivistas, sino algo intermedio, proveniente de la naturalis ratio, de la naturaleza de la cosas, de la aequitas y de la llamada lógica jurídica.

Incluso, ya con anterioridad BoulangeR ${ }^{27}$ hubo de publicar el que fuera considerado por el propio Esser como el primer estudio analítico sobre los tipos y las categorías de principios jurídicos. $^{28}$ Para este autor francés, la distinción entre reglas y principios se resume en que mientras una regla es general porque ella se crea para un número no determinado de actos o hechos, un principio es general porque implica una serie indefinida de aplicaciones. En esta dirección, la distinción es viable pues mientras la regla tiene una situación jurídica determinada a la cual se aplica (aunque no se crea para un número determinado de dichas situaciones jurídicas), un principio no tiene una única situación jurídica a la cual se aplica. ${ }^{29}$

En el ámbito legislativo, entre varios acontecimientos con valor ejemplificativo acaecidos durante la vigésima centuria, cabe mencionar dos de ellos por el impacto doctrinario que supusieron. En primer lugar, la regulación de los principios generales del Derecho en el sistema de fuentes formales del Derecho Internacional Público al amparo del inciso c del artículo 38-1 del Estatuto de la Corte Internacional de Justicia, lo que equivale al reconocimiento de los principios como normas de aplicación directa con vocación para incidir tanto en el fondo de un asunto como en el procedimiento particular de su tramitación, en calidad fuente autónoma, y como elementos de complementación de los mandatos emanados de los tratados y de la costumbre internacional. ${ }^{30}$

\footnotetext{
27 Cfr. Boulanger, J., "Principes généraux du droit et droit positif," en Le Droit privé français au milieu du XXe siècle. Études offertes a Georges Ripert, tomo I, Paris, Librairie Générale de Droit et de Jurisprudence, 1952, pp. 51-74.

28 Cfr. Esser, J., Principio..., op. cit., pp. 17-18.

29 Boulanger, J., "Principes...," op. cit., pp. 51-74. Este análisis se puede encontrar en Grau, E. R., Interpretación y Aplicación del Derecho, Madrid, Dykinson, 2007, p. 162.
} 
En segundo lugar, por la ascendencia iusfilosófica del debate que generó, destaca el suceso de recodificación italiana que concluyó con la promulgación del Codice de 1942 que, en giro copernicano, adoptó en su artículo 12 una directriz iuspositivista al sustituir la locución principi generali del Diritto, contenida en su antecesor de 1865, por la de principi generali dell'ordinamento giuridico. La razón del cambio, que había sido debatido durante la década de 1930 en los trabajos preparativos del cuerpo legal, se justificó como una medida de protección ante la intromisión de elementos extraños en la dinámica del ordenamiento jurídico. ${ }^{31}$ En la doctrina interna, CARNELuTTI apoyó la reforma, ${ }^{32}$ mientras que Del Vecchio se pronunció con fuerza en su contra, catalogándola de retroceso y tildando la nueva expresión de impropia, llegando a concluir se trató de una fórmula inspirada en un sórdido positivismo y en una miope estatolatría, con la que se intentaba cerrar la entrada al Derecho natural, como fuente supletoria del sistema vigente. ${ }^{33}$

De cualquier modo, al día de hoy es innegable que las tesis sobre los principios han sido uno de los animadores más destacados de la discusión teórica y filosófica sobre el Derecho de los últimos tiempos, proyectándose sobre tópicos tan centrales

30 Vid, entre otros, Verdross, A., Derecho Internacional Público, Madrid, Aguilar, 1957, pp. 123 124; Pastor Ridruejo, J. A., Fundamentación y fuentes del derecho internacional (distintas a los tratados), Madrid, Curso impartido en la Escuela Diplomática, 1971-1972, pp. 17 y ss; y Velázouez Elizarrarás, J. C., "Reflexiones generales en torno a la importancia de los principios del derecho internacional," en Anuario Mexicano de Derecho Internacional, México, vol. XII, Instituto de Investigaciones Jurídicas de la UNAM, 2012, p. 115. En la doctrina cubana el criterio más representativo ha sido expuesto por Sánchez de Bustamante y Sirvén, A., Manual de Derecho Internacional Público, La Habana, Talleres Tipográficos La Mercantil, 1945, pp. 14 y ss.

31 Cfr. BobBı, N., Teoría general del Derecho, Madrid, Debate, 1998, pp. 249-250; y TraBucchi, A., Istituzioni di Diritto Civile, Padova, CEDAM, Casa Editrice Dott, Antonio Milani, 1956, pp. 28 y ss.

32 En expresión de este autor los principios del Derecho son "(...) las reglas no expresadas de que derivan, a través de su aplicación a los casos previstos, los preceptos formulados con carácter general o particular (...)." CARneluttı, F., Teoría General del Derecho, Madrid, Revista de Derecho Privado, 1941, p. 118.

33 Del Vecchio, G., "Riforma del Codice civile e principi generali del Diritto," en Rivista Internazionale di Filosofia del Diritto, Roma, ano XVIII, fascículo I, 1938, in integrum. 
como las relaciones de lo jurídico con lo moral, la tipología de las disposiciones jurídicas, la caracterización de los casos difíciles, la creación judicial del Derecho, el carácter y estructura del razonamiento jurídico justificativo, entre otros. ${ }^{34}$

En el desarrollo del pensamiento jurídico del siglo XX occidental, la construcción de teorías principalistas, o de referencia a los principios, se ha manifestado desde flancos diversos. Sin ánimo de exhaustividad, y siguiendo a Poscher, ${ }^{35}$ se puede establecer una propuesta de sistematización atendiendo a cinco grandes tendencias, a saber:

1. Como tendencia propia del contexto anglosajón, la teoría principalista se ha configurado, en los marcos del debate iniciado por HART y Dworkin, en los espacios de las reflexiones estructurales sobre el Derecho. Es decir, en los estudios sobre las características de los ordenamientos jurídicos en su relación con otros fenómenos normativos, como pueden ser los establecidos por la moral y la política. ${ }^{36}$

2. Como epicentro de la teoría de las normas, la diferenciación entre reglas y principios se ha presentado como presupuesto del análisis lógico del Derecho. Como expresiones notables de esta tendencia se presentan los estudios de Alexy y de Guastini. ${ }^{37}$ Como es posible advertir, opera aquí una importante particularización analítica, pues el objetivo no es disertar sobre las características de un orden normativo jurídico y su vinculación con otros ordenes normativos

34 Apud Atienza, M., y J. Ruiz Manero., Las piezas..., op. cit., p. 2.

35 Cfr. Poscher, R., "Aciertos, errores y falso autoconcepto de la teoría de los principios," en Sieckmann, J-R., (editor), La teoría principalista de los derechos fundamentales. Estudios sobre la teoría de los derechos fundamentales de Robert Alexy, Madrid, Marcial Pons, 2011, pp. 7172. También vid ÁvILA, H., Theory of Legal Principles, The Netherlands, Springer, Dordrecht, 2007, pp. 5-82.

36 Cfr. HaRt, H. L. A., El concepto de Derecho, Buenos Aires, Abeledo-Perrot, 1961, pp. 33 y ss; y Dworkin, R., Los derechos en serio, Barcelona, Ariel, 1989, pp. 61 y ss.

37 Cfr. Guastinı, R., Interpretar..., op. cit., pp. 183 y ss; GuAstinı, R., La sintaxis del Derecho, Madrid, Marcial Pons, 2016, pp. 75 y ss; y GuAstinı, R., Ensayos escépticos sobre la interpretación, Perú, Zela, 2018, pp. 140 y ss. 
presentes en la sociedad, sino sobre las características y la estructura lógica de las distintas normas jurídicas. En sentido genérico, las tesis de distinción suelen agruparse en dos rubros opuestos, a saber, las tesis fuertes y las tesis débiles. ${ }^{38}$ La tesis débil enuncia que la diferencia entre principios y reglas es meramente de grado, ${ }^{39}$ es decir, hace referencia al mayor o menor nivel de generalidad o abstracción que presenten estos tipos de normas. En sentido divergente, la tesis fuerte afirma que la diferencia entre principios y reglas no es meramente de grado, sino que además existen propiedades lógicas o estructurales que diferencian a las reglas de los principios, ${ }^{40}$ esto es, que se puede realizar un ejercicio de clasificación normativa que tiene a las reglas y a los principios como alternativas.

3. La teoría de los principios ha sostenido, igualmente, una compleja teoría de metodología jurídica relativa a la aplicación del Derecho. Como desprendimiento de la diferenciación entre reglas y principios, se han defendido formas categorialmente distintas para hacer efectiva su aplicación, a saber, la subsunción como forma básica de aplicación de las reglas, y la ponderación como forma básica de aplicación de los principios. ${ }^{41}$

38 Cfr. Bayón, J. C., La normatividad del derecho. Deber jurídico y razones para la acción, Madrid, Centro de Estudios Políticos y Constitucionales, 1991, p. 359; y García FigueroA, A., Principios y positivismo jurídico. El no positivismo principialista en las teorías de Ronald Dworkin y Robert Alexy, Madrid, Centro de Estudios Políticos y Constitucionales, 1998, p. 132;

39 Cfr. Hart, H. L. A., "Postcriptum," en Rodríguez, C., La decisión judicial. El debate HartDworkin, Bogotá, Siglo del Hombre, 1997, p. 199; y Raz, J., "Legal Principles and the Limits of Law," en The Yale Law Journal, vol. 81, no. 5, 1972, p. 838.

40 Cfr. Alexy, R., Teoría..., op. cit., pp. 81 y ss; Dworkin, R., Los derechos..., op. cit., pp. 61 y ss; y Atienza, M., y J. Ruiz Manero., Las piezas..., op. cit., p. 29.

41 Cfr. Alexy, R., Teoría..., op. cit., pp. 89 y ss. Además vid Martínez Zorrilla, D., Conflictos constitucionales, ponderación e indeterminación normativa, Madrid, Marcial Pons, 2007, pp. 149 y ss; Bernal Pulido, C., El principio de proporcionalidad y los derechos fundamentales. El principio de proporcionalidad como criterio para determinar el contenido de los derechos fundamentales vinculante para el Legislador, Bogotá, Universidad Externado de Colombia, 2014, pp. 736 y ss; BARAK, A., Proporcionalidad. Los derechos fundamentales y sus restricciones, Lima, Palestra, 2017, pp. 109 y ss. 
4. La teoría de los principios como presupuesto para la concepción de una teoría de la argumentación jurídica coherente, esto es, la necesidad de incluir a los principios en los ejercicios de fundamentación en el ámbito del Derecho, o más aún, de conceptualizar a los principios como argumentos. Resultan de interés en este rubro los criterios de Sieckmann ${ }^{42}$ y de Esser, y, más cercanos en el tiempo, los estudios realizados por Atienza y su postulación de una visión del Derecho como fenómeno argumentativo. ${ }^{43}$

5. La teoría de los principios se encuentra conectada igualmente con toda una estela de reflexión sobre la dogmática de los derechos fundamentales. La exposición clásica al respecto ha sido presentada por Alexy, que entiende que los derechos fundamentales son principios y estos mandatos de optimización. ${ }^{44}$ Consonantemente, la colisión de derechos fundamentales, que es un cuadro constante al que se enfrenta la actividad judicial, no es otra cosa de una colisión de principios que requiere para su solución de recreación de un razonamiento ponderativo, que en el caso de la teoría alexyana se integra en una estructura mucho más compleja, a saber, el principio de proporcionalidad.

Seguidamente se presentarán las líneas generales que informan el desarrollo de cada uno de estos cinco derroteros teórico-prácticos.

42 Cfr. Sieckmann, J., "Concepto y estructura de las reglas, principios y elementos en el derecho," en El modelo de los principios del derecho, Bogotá, Universidad Externado de Colombia, 2006, pp. 59-80. Además, vid de este autor los trabajos "Las estructuras lógicas de los argumentos normativos," "Corrección y objetividad en el modelo de principios," "Ponderación autónoma," y "Sobre la fundamentación de los juicios ponderativos," todos en El modelo..., op. cit., pp. 81-114, 235-284, 115-158 y 159-205.

43 Cfr. Atienza, M., Las razones del derecho. Teorías de la argumentación jurídica, México, UNAM, 2005, pp. 203 y ss; y AtienZA, M., Curso de argumentación jurídica, Madrid, Trotta, 2013, pp. 19 y ss.

44 Cfr. Alexy, R., Teoría..., op. cit., pp. 48 y ss. También vid la sistematización de Bernal Pulido, C., "Los derechos fundamentales y la teoría de los principios. ¿Es la teoría de los principios la base para una teoría adecuada de los derechos fundamentales de la Constitución española?" en Doxa, Alicante, no. 30, 2007, pp. 273-191. 


\section{El discurso sobre los principios como concepción anti-iuspositivista del Derecho}

Con anterioridad quedó esbozado que toda teoría principalista es en cierto sentido un cuestionamiento al positivismo jurídico. Tal y como sentenció García Figueroa, “(...) si existen principios en el Derecho, entonces es inviable una concepción positivista del Derecho (...);" 45 idea que fuera también compartida por ZagreBeLSKY, a cuyo juicio “(...) hoy sería imposible un positivismo de los principios (...)." ${ }^{46}$ Este cuestionamiento ha recaído de forma preponderante en lo que respecta a la incorporación de la moral al Derecho, problemática que se ha mostrado constante en la iusfilosofía occidental, especialmente desde las críticas de RADBRUCH a las consecuencias del legalismo nazi, sustentadas en la estandarización de la justicia como parámetro de validez jurídica, ${ }^{47}$ involucrando con esto a otras postulaciones básicas del iuspositivismo. Incluso, si acepta la diferenciación establecida por Boввіо, ${ }^{48}$ la variante del positivismo jurídico metodológico, mucho más depurada que las acepciones ideológicas y teóricas, tampoco puede ser compatible con una teoría de los principios, al menos en su sentido fuerte, precisamente porque la tesis fundamental de esta concepción radica en que el Derecho "(...) es un fenómeno social que puede ser identificado y descrito por un observador externo sin recurrir a consideraciones acerca de su justificación o valor moral o acerca del deber moral de obedecerlo y aplicarlo (...)." ${ }^{49}$ En efecto, la aceptación de que los ordenamientos

\footnotetext{
45 García Figueroa, A., Principios..., op. cit., p. 29.

46 Zagrebelsky, G., El derecho dúctil. Ley, derechos, justicia, Madrid, Trotta, 2005, p. 124

47 Cfr. Radbruch, G., Introducción a la Filosofía del Derecho, México DF, Fondo de Cultura Económica, 1998, p. 178.
}

48 Cfr. Bobвı, N., El problema del positivismo jurídico, Buenos Aires, Editorial Universitaria, 1965.

49 Nino, C. S., La validez del derecho, Buenos Aires, Astrea, 1985, p. 148. También vid Raz, J., Entre la autoridad y la interpretación. Sobre la teoría del derecho y la razón práctica, Madrid, Marcial Pons, 2013, pp. 177 y ss; Orunesu, C., Positivismo jurídico y sistemas constitucionales, 
jurídicos actuales contengan normas con tipología de principios recalca la posibilidad de instrumentalización de la moral en los espacios de interpretación, aplicación y argumentación en el Derecho.

Una primera razón se centra en el hecho de que los principios generalmente son contentivos de conceptos esencialmente controvertidos que suponen un debate moral, constituyendo un ejemplo nítido lo relativo al contenido de los derechos fundamentales, cuya delimitación, como tendrá ocasión de explicarse, supone implicaciones morales. Esta propensión moral denota que la teoría de los principios, como ha advertido Prieto SANCHís, "(...) servirá de vehículo privilegiado a las sucesivas rehabilitaciones del iusnaturalismo (...)."50

Para explicitar correctamente esta cuestión, que concierne en la posibilidad de entender a la moral como una condición de validez jurídica, se hace necesario dejar sentado que además de la tesis de la separación entre el Derecho y la moral, el positivismo ha planteado otras dos ideas que le resultan esenciales, a saber, la tesis de las fuentes sociales, que hace depender la existencia y el contenido del Derecho en un sociedad de un conjunto de hechos sociales; y la tesis de la discrecionalidad, que plantea que las normas jurídicas válidas no regulan de manera clara todo caso individual, de manera que ante los denominados casos difíciles los jueces actúan discrecionalmente. ${ }^{51}$ Ahora bien, los principios contradicen la concepción iuspositivista en tanto no integran el Derecho en atención de alguna fuente social, sino por su propio contenido, es decir,

Madrid, Marcial Pons, 2012, pp. 213 y ss; y Celano, B., "Positivismo jurídico normativo, neutralidad y estado de Derecho," en Ferrer Beltrán, J., et al., (editores), Neutralidad y teoría del Derecho, Madrid, Marcial Pons, 2012, pp. 243-274.

50 Prieto Sanchís, L., Sobre principios y normas, Madrid, Centro de Estudios Constitucionales, 1992, p. 68.

51 Cfr. Moreso, J. J., "Positivismo jurídico contemporáneo," en Fabra Zamora, J. L., y Á. Núñez Vaquero., (editores), Enciclopedia de Filosofía y Teoría del Derecho, vol. I, México, Instituto de Investigaciones Jurídicas de la UNAM, 2015, pp. 171-205. 
los principios no son jurídicamente vinculante por su origen (descrito por ejemplo al tenor de una regla de reconocimiento) sino por sus méritos sustantivos. Es por esto que VIGo ha sostenido que "(..) los principios fuertes postulan una noción de validez que excede la mera pertenencia autoritativa al sistema jurídico (...)." ${ }^{52}$ Se desprende entonces que sin los jueces pueden aplicar principios, y estos debido a sus características no pueden ser identificados por ningún test de origen, entonces no sería posible establecer un límite estricto entre el Derecho que es y el Derecho que debería ser. Fue en este sentido que Dworkin recalcó que si los principios morales son jurídicamente vinculantes por cuestiones sustantivas, entonces la moral pude ser considerada como una condición de validez jurídica, ${ }^{53}$ lo que deja sin virtualidad la tesis de la separación, a la par que la tesis de la discrecionalidad, pues siempre existirá un principio que pueda guiar la decisión del juez, incluso en los casos de ausencia de reglas.

Otra razón, que metodológicamente es una operación posterior, interesa a la necesidad de crear criterios móviles de precedencia de un principio con respecto a otro en supuestos de colisión ante la solución de un caso concreto. Estos criterios de precedencia se instrumentalizan en ocasión de la ponderación, y como ha señalado el profesor Vilajosana, “(...) al menos en la mayoría de los casos (...) los ha de proporcionar una teoría político-moral, más o menos desarrollada (...)." 54

Esta última dirección de la incorporación moral, precisada en la resolución de colisiones principiales, ha sido descrita con mucha coherencia por AlExy, para quien toda colisión entre principios puede expresarse como una colisión entre valores y viceversa. Para este autor la única diferencia entre estos

\footnotetext{
52 Vigo, R. L., De la ley al Derecho, México, Porrúa, 2012, p. 267.

53 Cfr. Dworkin, R., Los derechos..., op. cit., pp. 80-83.

54 Vilajosana Rubio, J. M., “De lo posible a lo deseable. Las circunstancias de la jurisdicción y de la política en democracia," en Vázouez, R., et. al., Democracia, religión y Constitución, Madrid-México, Fundación Coloquio Jurídico Europeo, Fontamara, 2010, pp. 169-170.
} 
posibles tipos de colisión radica en que la que se presenta entre principios se trata de la cuestión de qué es debido de manera definitiva, mientras que la solución a la que se presenta entre valores contesta a qué es de manera definitiva mejor. ${ }^{55}$ En conclusión, principios y valores son lo mismo, solo siendo variable la perspectiva de análisis, de naturaleza deontológica en el primer caso y de naturaleza axiológica en el segundo, constituyendo esta peculiaridad un argumento demostrativo de que el problema de las relaciones de prioridad entre principios se corresponde con el problema de una jerarquía de los valores.

Las razones expuestas, entre otras que ilustran el antiiuspositivismo que entraña la apología del principalismo, han provocado una especie de redimensionamiento $a b$ intra de la propia tendencia iuspositivista. Ciertamente, y como tuvo a bien señalar ORUnesu, la teoría de los principios ha forzado a los iuspositivistas "(...) a explicar el hecho aparente de que los principios morales pueden a veces ser fuentes jurídicas válidas, de un modo que resultara consistente con sus tesis básicas (...)." ${ }^{56}$ Una de estas redimensiones se ha cristalizado en el llamado positivismo incluyente, que en oposición al positivismo excluyente, admite que la moral puede ser condición de validez jurídica en ciertos sistemas jurídicos en los que la existencia y el contenido del Derecho dependerá de valoraciones y principios morales. ${ }^{57}$ Este es el caso, por ejemplo, de los esquemas de las democracias constitucionales contemporáneas, caracterizados por una amplia incorporación de principios morales en los textos constitucionales, frecuentemente invocados por los jueces (especialmente los jueces constitucionales) para determinar la validez (constitucionalidad) de las leyes. De estos principios constitucionales

\footnotetext{
55 Alexy, R., "Sistema jurídico, principios y razón práctica," en Ensayos sobre la teoría de los principios y el juicio de proporcionalidad, Lima, Palestra, 2019, p. 48.

56 Orunesu, C., et. al., Estudios sobre la interpretación y dinámica de los sistemas constitucionales, México, Fontamara, 2009, p. 62.

57 Un estudio riguroso al respecto en Jiménez Cano, R. M., Una metateoría del positivismo jurídico, Madrid, Marcial Pons, 2008, pp. 205-218.
} 
“(..) resultan predicables las mismas características que el pluralismo atribuye a los valores: objetividad, pluralidad, conflictividad, inconmensurabilidad, indeterminación (.....". ${ }^{58}$

Esto supone una identificación mayoritaria de principios en los textos constitucionales, los que se presentan como cánones de moralidad, como directrices de interpretación y como elementos en pos de una óptima argumentación tanto jurisdiccional como legislativa. Tal circunstancia ha dado al traste con una serie de postulados que, bajo el rubro común de constitucionalismo principalista, plantean que aunque los principios no sean una peculiaridad absoluta de los textos constitucionales, sí que es cierto que en él, en sintonía con Pozzolo, “(...) se encuentran presentes en un número particularmente elevado (...) hasta determinar un cambio cualitativo del documento (......"59

En conclusión, el asunto de los principios, en negación de las propuestas fundacionales del iuspositivismo, da muestra de lo ambigua que puede resultar la línea divisoria entre el Derecho y la moral en el campo de las decisiones jurídicas, ya que su estatus como fuentes del Derecho depende únicamente del contexto en el que son utilizados. ${ }^{60}$

\section{El discurso sobre los principios como teoría normativa. La distinción con las reglas}

El desarrollo del principalismo en el siglo XX, tal y como quedó anunciado supra, ha tenido como uno de sus derroteros fundamentales a la estructuración de una teoría de las normas jurídicas con epicentro en la distinción entre reglas y principios. La posibilidad de distinguir tipologías normativas consistentes

\footnotetext{
58 Barberis, M., "Pluralismo de los valores, nuevo constitucionalismo y balance libertadseguridad," en Doxa, Alicante, no. 39, 2016, pp. 272-273.

59 Pozzolo, S., "Neoconstitucionalismo y especificidad de la interpretación constitucional," en Doxa, Alicante, no. 21-II, 1998, p. 340.

60 Cfr. Aarnio, A., Lo racional como razonable. Un tratado sobre la justificación jurídica, Lima, Palestra, 2016, pp. 152-153.
} 
en reglas y principios ha catalizado los estudios de lógica jurídica, de teoría de la interpretación y de metodología de aplicación del Derecho.

Las cuestiones de lógica jurídica han reparado en diferencias estructurales y funcionales propias de los enunciados jurídicos normativos, que hacen plausible entenderlos como reglas o principios según se constaten determinadas características morfológicas. Los desarrollos de esta tendencia se agrupan en derredor de la llamada tesis fuerte de distinción, asumiendo como presupuesto que estos tipos de normas entrañan proposiciones lógicas diferenciadas, es decir, reglas y principios son formas clasificatorias de las normas. En otra dirección, las teorías de la interpretación han configurado una tesis débil de distinción, postulando que la diferenciación entre reglas y principios solo se puede establecer como resultante de un ejercicio interpretativo, argumental y discursivo, no siendo posible concebir en este sentido un criterio estrictamente ontológico, corroborándose de esta forma el sentido de la máxima de AARNIO, según la cual reglas y principios “(...) pueden tener teóricamente el mismo grado de inexactitud, y por lo tanto resulta imposible separarlos en categorías lingüísticas nítidamente distintas (...)." ${ }^{\prime 1}$ Esta tesis vinculada a la interpretación concluye que la divergencia entre reglas y principios es meramente de grado, es decir, pende del nivel de generalidad que se les atribuya. ${ }^{62}$ Finalmente, en lo que a metodología de la aplicación del

61 Cfr. Aarnio, A., "Reglas y principios en el razonamiento jurídico", en Anuario da Facultade de Dereito da Universidade da Coruña, no. 4, 2000, p. 597.

62 El posicionamiento más definido de esta tesis corresponde a GuASTINI. La diferenciación entre reglas y principios es explicada por este autor a través de un método descriptivo que parte de establecer una serie de características distintivas. Las reglas, en este sentido, pueden ser asumidas como enunciados condicionales que establecen una conexión entre una determinada consecuencia jurídica a una clase de hechos. Es decir, son normas cuya estructura se expresa en la construcción lógica si $A$, entonces $B$. Por el contrario, los principios no comparten esta delimitación, siendo caracterizados por GuAstinı en atención a dos parámetros: 1-) son normas que tienen un carácter fundamental; y 2-) son normas sujetas a una especial forma de indeterminación. Ahora bien, para GUASTINI el carácter fundamental o marginal de una norma, su carácter derrotable o inderrotable, y (en muchos casos) el 
Derecho compete, el principalismo se ha construido como una teoría analítica cuya formulación esencial consiste, como bien ha sintetizado Borowski, “(...) en que en el caso de colisiones entre un determinado tipo de normas -los principios- no se trata de que una de ambas normas ha de ser inválida, sino que se produce un retroceso de una de las normas en el caso concreto sin pérdida de su validez (...)." ${ }^{63}$ Es decir, desde la metodología aplicativa lo trascendente es que reglas y principios, en tanto normas diferentes, son aplicadas mediante mecanismos diferentes, a saber, la subsunción y la ponderación respectivamente, operando dimensiones también distintas en casos de colisión, estas son, la dimensión de la validez para las reglas y la dimensión del peso para los principios.

Como se observa, una concepción coherente que distinga entre reglas y principios trasciende a espacios esenciales de la dinámica jurídica, tales como la interpretación, la jerarquización y los criterios de validez de las normas y las peculiaridades de sus modelos de aplicación. Es por este nivel de trascendencia que la diferenciación de reglas y principios se presenta como una de las bases de la teoría contemporánea de las normas jurídicas. Ahora bien, como demarcó DE FAzIO, los partidarios del principalismo en sentido estricto suscriben una tesis fuerte de distinción, ${ }^{64}$ pues solo a su tenor se puede afirmar que los sistemas jurídicos están formados por normas de mandato que pueden asumir la tipología de reglas o la tipología de principios. Por esta razón, serán las particularidades de esta tesis las que se pondrán de relieve en la propuesta discursiva del presente

carácter abierto o cerrado de un supuesto de hecho no son datos objetivos, anteriores a la interpretación: al contrario, dependen de la interpretación, son fruto de la interpretación (entendida en sentido lato). Cfr. Guastinı, R., Interpretar..., op. cit., pp. 183-190 y 190-191; Guastinı, R., La sintaxis..., op. cit., pp. 75-79; Guastinı, R., Ensayos..., op. cit., pp. 140-144; y Guastinı, R., Las fuentes del derecho. Fundamentos teóricos, Lima, Editorial Científica Peruana, 2016, pp. 325-333.

63 Borowski, M., "Derechos de defensa como principios de derecho fundamental," en SIECKMANn, J-R., (editor), La teoría..., op. cit., p. 95.

64 Apud De Fazıo, F., "La teoría...," op. cit., p. 46. 
epígrafe, adelantándose además que la misma se suscribe como propuesta teórico-normativa.

En el entorno continental, como quedo esbozado con anterioridad, los primeros criterios de distinción entre reglas y principios estuvieron contenidos en las reacciones al positivismo normativista de KELSEN. Específicamente, la distinción primaria de Boulanger, sustentada en el criterio de generalidad a favor de los principios, y en detrimento de las reglas, en cuanto a las situaciones jurídicas a las que pueden ser aplicados ${ }^{65} \mathrm{y}$, posteriormente, las explicaciones de EssER relativas a la conceptualización de los principios como topoi, alejados de cualquier síntoma de carácter cerrado y estático, que utilizan constantemente los jueces para conjugar la solución más justa a los controvertidos, ${ }^{66}$ fueron cuestionamientos de peso al esquema de pureza metodológica descrito en las obras kelsenianas.

No obstante, es forzoso admitir que la configuración de una teoría de las normas jurídicas apoyada en la escisión entre reglas y principios tuvo su expresión fundante más exhaustiva en los estudios jurídicos del mundo anglosajón, muy especialmente en los cuestionamientos de Dworkin al positivismo de HART, los que se pueden resumir es dos posiciones. La primera posición está dirigida a establecer que la regla de reconocimiento no es óptima para identificar principios jurídicos implícitos, mientras que la segunda recrea que no es posible construir un test preciso que permita elucidar cuándo un enunciado normativo es un principio implícito de un determinado sistema jurídico, entre otras razones porque la distinción entre creación y aplicación de normas tipo reglas no es trasladable a los principios implícitos. ${ }^{67}$ De hecho, la construcción de una teoría de las normas alternativa a la propuesta hartiana del sistema de reglas estructurado en derredor de la regla de reconocimiento, es una

\footnotetext{
65 Cfr. Boulanger, J., “Principes...," op. cit., pp. 51-74.

66 Cfr. Esser, J., Principio..., op. cit., pp. 169 y ss.

67 Cfr. Alonso, J. P., “Principios implícitos y fuentes sociales del Derecho," en Doxa, Alicante, no. 41, 2018, p. 64.
} 
de las consecuencias fundamentales de la ya aludida negación del dogma de la separación entre el Derecho y la moral que propuso Dworkin desde sus primeros trabajos.

Hurgando en la historia jurisprudencial de los Estados Unidos, Dworkin prestó atención especial a un caso decidido por el Tribunal de Apelaciones de New York el 8 de octubre de 1889, cuya denominación simplificada es Riggs vs. Palmer. ${ }^{68}$ La solución del caso a través de la aplicación de un principio demuestra, según Dworkin, que la tesis de las fuentes sociales ${ }^{69}$ no es suficiente para explicar la dinámica jurídica, pues este no tiene su justificación en ninguna práctica social anterior, sino en su pertinencia para justificar una toma de partido. ${ }^{70}$ La separación entre el Derecho y la moral ${ }^{71}$ también pierde virtualidad en este análisis, pues, justamente, es la legitimación ética del principio lo que lo hizo apto para resolver el asunto, esto es, lo que hizo pertinente desarrollar todo un aparato argumentativo en pos de llegar a una solución coherente y aceptable ${ }^{72}$ que, igualmente, atenta contra la tesis de la discrecionalidad, ${ }^{73}$ pues en el supuesto de no contar el juez con una regla aplicable

68 Cfr. Philo Riggs, como curadora ad Litem et al., Demandantes, contra Elmer E. Palmer et al., Demandados. Tribunal de Apelaciones de Nueva York. Demanda presentada el 21 de junio de 1889. Demanda resuelta el 8 de octubre de 1889.

69 HART, H. L. A., El concepto..., op. cit., pp. 125-126 y 137. Un análisis de valor en Alonso, J. P., "Principios...," op. cit., pp. 63-82.

70 Apud Dworkin, R., Justicia para erizos, México, Fondo de Cultura Económica, 2014, pp. 41 y ss.

71 Hart, H. L. A., El concepto..., op. cit., p. 230. También vid Moreso, J. J., y J. Queralt., "Bosquejo de Dworkin: la imbricación entre el Derecho y la moralidad," en Isonomía, no. 41, octubre de 2014, pp. 143-171.

72 Explicaba Dworkin que un principio como nadie puede beneficiarse de su propio delito no pretende establecer "(...) las condiciones que hacen necesaria su aplicación. Más bien enuncia una razón que discurre en una sola dirección, pero no exige una decisión en particu$\operatorname{lar}($.... . Cuando decimos que un determinado principio es un principio de nuestro derecho, lo que eso quiere decir es que el principio es tal que los funcionarios deben tenerlo en cuenta, (...) como criterio que les determine a inclinarse en uno u otro sentido (...)." Dworkin, R., Los derechos..., op. cit., pp. 76-77.

73 Hart, H. L. A., El concepto..., op. cit., p. 161. 
al caso controvertido, está en la obligación de aplicar el principio idóneo. ${ }^{74}$

La dicotomía entre reglas y principios es enfocada por Dworkin en un doble sentido, a saber, el modo de aplicación, que para las reglas es de todo o nada, es decir, que si se cumple con su supuesto de hecho, entonces o bien la regla es válida y su consecuencia jurídica determina concluyentemente la decisión, o bien es inválida y no aporta en nada a la sentencia, mientras que los principios no se aplican de esta manera, pues cuando resulten válidos y se cumpla con su supuesto de hecho estos no necesariamente determinan consecuencias jurídicas de manera automática. ${ }^{75}$ En cambio, estos solamente enuncian una razón que discurre en una dirección, pero que puede quedar desplazada en virtud de algún otro principio que apunta en una dirección contraria; y la distinción de la dimensión de peso de los principios, lo que significa que las contradicciones entre principios se deciden mediante la selección del que más peso (importancia) suponga en ocasión del caso concreto, no significando esta selección un desplazamiento de la validez del otro principio contrincante. Esta operación no es posible realizarla en el campo de las reglas, ya que en casos de colisiones entre ellas solo pueden ser solucionadas con la introducción de una cláusula de excepción o con la declaración de invalidez de, por lo menos, una de ellas. ${ }^{76}$

Esta línea de reflexión dworkiniana fue seguida por Alexy, siendo este iusfilósofo el autor del sistema más completo en la

\footnotetext{
74 Sin embargo, Atienza, siguiendo a MacCormick, sostuvo que "(...) el propio Hart consideró como característica del positivismo jurídico la tesis de la discrecionalidad judicial, es decir, la tesis de que en los casos dudosos o no previstos que aparecen en todo derecho, el juez crea derecho, aunque al mismo tiempo está sometido a una serie de cortapisas jurídicas que limitan su elección. Es más, a partir del positivismo jurídico de HART, no habría en principio ningún inconveniente para que el juez usara de los principios generales del derecho y de los tópicos jurídicos; bastaría con que lo admitiera la regla de reconocimiento del sistema en cuestión (...)."Atienza, M., Las razones..., op. cit., p. 74.

75 Cfr. Dworkin, R., Los derechos..., op. cit., pp. 73 y ss.

76 Cfr. Idem, pp. 73 y ss.
} 
materia. La reflexión alexyana parte de establecer que tanto las reglas como los principios son especies del género normas. ${ }^{77}$ Esta afirmación implica la asunción de una tesis fuerte de distinción, es decir, supone afirmar que la diferencia entre reglas y principios no es meramente de grado, sino de clasificación o de clase, dada la concurrencia de ciertas características estructurales que definen la divergencia. Esto último conduce a concluir que toda norma solamente puede ser o bien un principio o bien una regla, sin que puedan caber modalidades intermedias.

Después de analizar los criterios manejados por Dworkin, AleXY postula que el punto decisivo para la distinción entre reglas y principios es que los principios son normas que ordenan que se realice algo en la mayor medida posible, esto en relación con determinadas posibilidades jurídicas y fácticas. Así, los principios son “(...) mandatos de optimización que se caracterizan porque pueden ser cumplidos en diversos grados y porque la medida ordenada de su cumplimiento no sólo depende de las posibilidades fácticas, sino también de las posibilidades jurídicas. El campo de las posibilidades jurídicas está determinado a través de principios y reglas que juegan en sentido contrario (...)."78

Las reglas, en oposición, son normas que exigen un cumplimiento pleno, es decir, respecto a ellas solo cabe la configuración de un estado de cumplimiento o de incumplimiento, sin más precisiones. La validez de una regla es entonces indicativa de la obligatoriedad que respecto a la realización de su contenido pesa sobre sus destinatarios. Es por esto que las reglas contienen determinaciones en el campo de lo fáctica y jurídicamente posible. Recalca en consecuencia Alexy que “(...) lo importante, por ello, no es si la manera de actuar a que se refiere la regla puede o no ser realizada en distintos grados.

77 Cfr. Alexy, R., "Hacia un concepto de los principios jurídicos," en Ensayos..., op. cit., pp. 17-42.

78 Alexy, R., "Sistema jurídico, principios y razón práctica," en Ensayos..., op. cit., p. 47. 
Hay por tanto distintos grados de cumplimiento (...)." ${ }^{79}$ En conclusión, si la norma supone la exigencia de su cumplimiento en la mayor medida posible en relación con las posibilidades jurídicas y fácticas concurrentes, esta norma debe ser asumida como un principio. En cambio, si la norma supone la exigencia de una determinada medida de cumplimiento, esta debe ser asumida como una regla.

Esta distinción de clase es fundamentada por Alexy sobre la base del criterio de individualización, indicativo de una dimensión propia de los principios, esta es, la dimensión de peso. El hecho que los principios puedan ser dotados de un peso especificado implica que ante una circunstancia de colisión, como puede ser la que se materializa en la superposición del contenido de dos derechos fundamentales, la solución debe tomar en consideración la importancia relativa que cado uno de los principios enfrentados suponen sobre la base de las peculiaridades del caso. Ahora bien, a diferencia de como sucede en el entorno de las reglas, la preponderancia de un principio con respecto a otro en un supuesto puntual no implica la invalidez del principio desplazado, ni tampoco que haya que introducírsele una nueva cláusula de excepción. Como el peso del principio que prevalece se colige de las circunstancias particulares del caso, el principio derrotado no pierde la posibilidad de seguir operando como una norma válida a tener en cuenta para la toma de decisiones futuras y que, incluso, puede obtener prioridad si, ante nuevas circunstancias, cuenta con una importancia relativa mayor.

Divergentemente, las contradicciones entre reglas se dirimen exclusivamente en la dimensión de la validez, o lo que es lo mismo, la solución ante la contingencia de una colisión de reglas solo puede operar con la declaración de invalidez de, al menos, una de ellas, o a través de la introducción de una cláusula de excepción. A modo de corolario, la regla invalidada o exceptuada deja de operar como norma válida, no solamente para el caso presente, sino también para los casos futuros.

79 Idem, p. 47. 
Evidentemente, la aceptación de la existencia de principios en el sistema jurídico incide en el carácter de este y en el concepto mismo de Derecho, ${ }^{80}$ que Alexy esquematiza en una trilogía de elementos, a saber, el de la legalidad conforme al ordenamiento jurídico, el de eficacia social y el de corrección material, ${ }^{81}$ específicamente, y en relación con la dimensión de este último elemento, en lo que concierne a la tesis positivista de la separación entre el Derecho y la moral. ${ }^{82}$ Los principios, que como se dijo representan una tarea de optimización y no solo un conjunto de normas caracterizadas por la vaguedad, entrañan importantes consecuencias morales, pues si bien la tarea optimizatoria en cuestión es formalmente jurídica, en su fondo es esencialmente moral, dado que su contenido es esencialmente moral.

Sintéticamente, y como corolario de la tesis explicada, es de advertir que la teoría principalista (en el sentido fuerte asumido) distingue las reglas de los principios en atención a su fuerza deóntica, a saber, los principios admiten una gradación de cumplimiento ya que entrañan una exigencia de optimización, mientras que las reglas ordenan sin la posibilidad de concurrencia de soluciones aplicativas intermedias. Además, la teoría principalista ha sostenido que las reglas y los principios presentan metodologías diferenciadas para su aplicación, siendo este el presupuesto de la ponderación, cuestión a la que se dedicará el apartado que sigue.

\section{Los principios y la metodología de la aplicación del Derecho. La ponderación}

La definición de la ponderación implica un posicionamiento desde la metodología de la ciencia del Derecho, y muy

80 Cfr. Alexy, R., El concepto y la naturaleza del Derecho, Madrid, Marcial Pons, 2008, pp. 73-96.

81 Cfr. Alexy, R., El concepto y la validez del Derecho y otros ensayos, Barcelona, Gedisa, 1997, p. 21.

82 Cfr. Alexy, R., "Sobre las relaciones necesarias entre el Derecho y la Moral," en Alexy, R., Derecho y razón práctica, México, Fontamara, 2006, pp. 43-69. 
especialmente desde la teoría de las normas jurídicas, pues debe reconocer como presupuesto la existencia de estructuras normativas diferentes de las reglas, es decir, debe participar de un juicio de afirmación con respecto a los principios. Es de observar, como ha indicado Aharon BARAK, que el ambiente jurídico no contiene solo a las disposiciones legales más cercanas, “(...) sino también los crecientes círculos concéntricos compuestos por los principios aceptados, por las finalidades básicas compartidas y por los criterios jurídicos fundamentales (...)." 83 La ponderación es, efectivamente, un criterio de diferenciación entre la categoría de los principios frente a la categoría de las reglas, entendidas ambas como tipos diferentes de normas jurídicas.

En términos generales, la ponderación puede ser definida como una de las formas básicas de aplicación de las normas, esto en el entendido de que a través de ella se aplican los principios, mientras que a través de la subsunción se aplican las reglas. No obstante, y más allá de los contornos de la aplicación del Derecho propiamente dicha, la ponderación supone importantes incidencias en lo relativo a la interpretación y a la argumentación en sede jurídica.

Si bien la ponderación cobra relevancia en todos los escenarios en los que se haga necesaria la aplicación de un principio, en tanto estos no pueden ser asumidos, tal cual lo son las reglas, como mandatos que se aplican a un caso concreto en términos de todo o nada, sino como normas cuyas posibilidades de realización dependen de la concurrencia de determinadas circunstancias fácticas y jurídicas, lo que supone una indiscutible gradación en el extensión de su contenido (pueden cumplirse en diversos grados), ${ }^{84}$ es lo cierto que su

\footnotetext{
83 Barak, A., Proporcionalidad..., op. cit., pp. 97-98.
}

84 Cfr. Alexy, R., Epílogo a la teoría de los derechos fundamentales, Madrid, Centro de Estudios Políticos y Constitucionales, 2002, pp. 23 y ss. Una reacción crítica en García Amado, J. A., “¿Qué es ponderar? Sobre implicaciones y riesgos de la ponderación," en Revista Iberoamericana de Argumentación, no. 13, Departamento de Lógica, Historia y Filosofía de la 
instrumentación más evidente tiene lugar en la solución de los episodios de colisión principial, los que a su vez tienen en el ámbito constitucional su entorno natural. ${ }^{85}$ En dicho ámbito se impone la ponderación tanto en los supuestos de colisión entre dos (o más) principios constitucionales, es decir, con regulación en el texto constitucional, como en los predios del control de constitucionalidad respecto a las disposiciones normativas de jerarquía inferior que, potencialmente, restringen o contravienen un bien jurídico constitucionalmente tutelado.

Se hace alusión entonces a una forma de tomar decisiones definida por la imperatividad de sopesar razones que interactúan a favor y en contra de soluciones que normativamente cuentan con un nivel de estandarización, trastocado o desfigurado por un conflicto circunstancial, a la par que a la forma de fundamentar estas decisiones y los resultados que de ellas se segregan, ${ }^{86}$ siendo esta especialidad la que diferencia a la ponderación de la subsunción. ${ }^{87}$ Este mecanismo de razonamiento, reflejo de la complejidad que a la aplicación del Derecho es

Ciencia, UNED, 2016, pp. 11-12; y en De Lora, P, “Tras el rastro de la ponderación," en Revista Española de Derecho Constitucional, Madrid, no. 60, 2000, pp. 263 y ss.

85 WebBer, G. C. N., "Proportionality, Balancing, and the Cult of Constitutional Rights Scholarship," en Canadian Journal of Law and Jurisprudence, Ottawa, vol. XXIII, 2010, pp. 179-202; AleINIKOFf, T. A., El Derecho Constitucional en la era de la ponderación, Lima, Palestra, 2010, pp. 31-32; y Guastinı, R., Distinguiendo. Estudios de teoría y metateoría del derecho, Barcelona, Gedisa, 1999, p. 167.

86 Cfr. Bernal Pulido, C., El principio..., op. cit., pp. 720-727. Una idea concordante en Portocarrero Quispe, J. A., "Ponderación," en Eunomía, no. 12, abril-septiembre de 2017, pp. 210-221. También vid el ilustrativo estudio desarrollado por De la SierRA, S., “La ponderación y su contexto. Una reflexión a título introductorio," en Ortega, L., y S. De La Sierra., Ponderación y Derecho Administrativo, Madrid, Marcial Pons, 2009, pp. 99-114.

87 La visión clásica de LARENZ califica a la subsunción como de participación limitada en la obtención de la premisa menor. Para este autor alemán la aplicación jurídica entraña siempre una valoración. No obstante, deja un espacio de posibilidad para los silogismos de subsunción en los supuestos de hecho que son configurados conceptualmente de un modo tan amplio -bien sea ya por el legislador o con ayuda de la Jurisprudencia científica- que permiten efectuar la integración, en la mayoría de los casos, en la forma lógica que esta figura establece. También entonces, “( ...) sigue siendo válido, ciertamente, que la subsunción presupone un enjuiciamiento del hecho, el cual, por su parte, no se refiere ya, en 
inherente, exige una aceptación de posicionamientos iusfilosóficos que trasciendan la exegesis y se adentren en las breñas del fenómeno jurídico desde una perspectiva holística.

Así, para brindar solución al caso $\mathbf{A}^{1}$, desarrollado en el contexto $\mathbf{X}$, se presentan como óptimas las construcciones jurídico-normativas $\mathbf{P}_{1}$ y $\mathbf{P}_{2}$, dotadas de sentido principial, cuyas consecuencias resolutivas exhiben notas distintivas no despreciables, motivo por el cual el intérprete debe dilucidar cuál de las variantes acopiadas exterioriza un mayor peso, ${ }^{88}$ o lo que es lo mismo, cuál de las variantes se eleva como la más adecuada para fungir como pauta de traducción jurídica para con la realidad social contenida en el caso, esto de acuerdo con una serie de factores de naturaleza múltiple que deben ser comprendidos en un ejercicio argumentativo consecuente.

El resultado de la ponderación lo constituye un enunciado de preferencia cuya forma lógica es la siguiente: el principio $\mathbf{P}_{\mathbf{1}}$ tiene más peso (más valor, resulta más idóneo) que el principio $\mathbf{P}_{2}$ en el contexto $\mathbf{X}$ en el que se desarrolla el caso $\mathbf{A}^{1}$. La utilización del término preferencia tiene una marcada intencionalidad, a saber, el enunciado descrito no indica la validez de $\mathbf{P}_{\mathbf{1}}$ y la invalidez de $\mathbf{P}_{2}$. El enunciado de preferencia (que en sí mismo es un juicio comparativo entre el peso de $\mathbf{P}_{1}$ y $\mathbf{P}_{2}$ ) resulta a su vez de un juicio comparativo entre las soluciones que al caso concreto aportan los principios $\mathbf{P}_{\mathbf{1}}$ y $\mathbf{P}_{\mathbf{2}}$, tomando en consideración la justicia y la racionalidad que estas suponen. ${ }^{89}$ En consecuencia,

último término, al silogismo, sino sólo a juicios de percepción y experiencia (...)." Larenz, K., Metodología de la Ciencia del Derecho, Barcelona, Ariel, 1980, p. 269.

88 Sobre este aspecto la profesora Laura CLÉRico anotó que la referencia a la ponderación ha de realizarse en alusión a un proceso de preparación de la determinación de la relación de prioridad o preferencia condicionada. En sus palabras, "( ...) se trata (...) de la determinación de la existencia de una regla-resultado de la ponderación que sea vinculante prima facie para la solución de la colisión sin ponderación y, si no fuere el caso, de la determinación del peso abstracto y concreto de los principios y de la intensidad de la interferencia (...)." CLérico, L., El exámen de proporcionalidad en el Derecho Constitucional, Buenos Aires, Eudeba, 2009, p. 200.

89 Cfr. Jansen, N., "Los fundamentos normativos de la ponderación racional en el derecho," en Sieckmann, J-R (ed.), La teoría..., op. cit., p. 58; y Martínez Zorrilla, D., Conflictos..., op. cit., p. 155. 
si la solución $\mathbf{S}_{\mathbf{1}}$ corresponde a la aplicación del principio $\mathbf{P}_{\mathbf{1}} \mathbf{y}$ la solución $\mathbf{S}_{2}$ corresponde a la aplicación del principio $\mathbf{P}_{2}$, la estimación de un mayor peso a favor del principio $\mathbf{P}_{\mathbf{1}}$ respecto al principio $\mathbf{P}_{2}$ depende de una mayor estimación de la justicia y la racionalidad que entraña la solución $\mathbf{S}_{\mathbf{1}}$ respecto a la solución $\mathbf{S}_{2}$, o viceversa. ${ }^{90}$ Ahora bien, la preferencia del principio $\mathbf{P}_{1}$ respecto al principio $\mathbf{P}_{2}$, y, por ende, la preferencia de la solución $\mathbf{S}_{1}$ respecto a la solución $\mathbf{S}_{2}$, es condicional, es decir, depende del contexto $\mathbf{X}$ en el que se desarrolla el caso $\mathbf{A}^{1}$. Ergo, la preferencia descrita no debe necesariamente cobrar vigor en el contexto $\mathbf{Y}$ en el que se desarrolla el caso $\mathbf{A}^{2}$, donde también se ha denotado una colisión entre los principios $\mathbf{P}_{\mathbf{1}}$ y $\mathbf{P}_{\mathbf{2}}$.

De lo anterior es posible colegir que la ponderación se manifiesta en una estructura de argumentación jurídica, pues supone la organización y el contrapunteo de argumentos, no brindando per se un criterio material determinante del contenido objetivo de los principios que, una vez entrados en colisión, deben ser sopesados. Una colisión de principios se configura cuando "(...) en un caso concreto son relevantes dos o más disposiciones jurídicas, que fundamentan prima facie dos normas incompatibles entre sí, y que pueden ser propuestas como soluciones para el caso (...)."91 La ponderación se cristaliza entonces en el establecimiento y la fundamentación suficiente de una relación de precedencia de un principio con respecto a otro, condicionada por factores fácticos y jurídicos.

Ahora bien, la manifestación de la ponderación en una estructura de argumentación jurídica tiene como función específica justificar un estado puntual de prioridad de un principio con respecto a otro. Esta prioridad es de naturaleza puntual porque depende la apreciación axiológica de las circunstancias fácticas y jurídicas que concurran en un caso concreto y no de los escalonamientos jerárquicos propios del sistema de fuentes.

90 Cfr. Guastinl, R., Ensayos..., op. cit., p. 149.

91 Bernal Pulido, C., “Estructura y límites de la ponderación”, en Doxa, Alicante, no. 26, 2003, p. 226. 
El hecho de que la ponderación suponga una preminencia principial concreta está dado por la no existencia de un criterio de jerarquía en la ordenación de los principios, pues de lo contrario no sería cosa diferente a un mecanismo abstracto de gradación de estos con posibilidad de ser generalizado para la solución de conflictos de esta naturaleza.

El contenido axiológico de los principios y las cargas argumentativas que impone la instrumentación de la ponderación dan al traste con la configuración de un giro argumentativo ${ }^{92}$ que en los días que corren tiene una preeminencia significativa, sobre todo el ámbito jurisdiccional. ${ }^{93}$ En el pensamiento de AlEXY, la ponderación es un subprincipio del principio de proporcionalidad, y este, según diserta Bernal Pulido, es una estructura argumentativa precisa, compuesta por varias cargas de argumentación, "(...) libre de contradicción, que clarifica cuáles son las variables fácticas y normativas relevantes para la aplicación de los principios (...)." ${ }^{44}$ Así, los principios no solo son objetos de la ponderación, ya que además constituyen razones para la realización de los juicios ponderativos. Los principios son en sí mismos argumentos normativos. ${ }^{95}$ Tiene razón entonces ATIEnza cuando califica de obvio el hecho de que "(...) esa nueva concepción del Derecho (y el fenómeno del constitucionalismo en cuanto tal) supone una mayor demanda de justificación, de argumentación, en el Derecho: tanto en términos cuantitativos como cualitativos. Y lleva también a que el razonamiento jurídico no pueda configurarse como un razonamiento insular: la argumentación

\footnotetext{
92 Apud Romero Martínez, J. M., Estudios sobre la argumentación jurídica principalista. Bases para la toma de decisiones judiciales, México, UNAM, 2017, pp. 59-130. Además, vid Moreso I Mateos, J. J., Lógica, argumentación e interpretación en el derecho, Barcelona, UOC, 2005, pp. 109 y ss.

93 Vid lBáÑEZ, P. A., y R. AlexY., Jueces y ponderación argumentativa, México, UNAM, 2016, pp. 53 y ss.

94 Bernal Pulido, C., Derechos, cambio constitucional y teoría jurídica. Escritos de Derecho Constitucional y Teoría del Derecho, Bogotá, Universidad Externado de Colombia, 2018, p. 394. 95 Sieckmann, J-R., "Los derechos fundamentales como principios," en Sieckmann, J-R., (editor), La teoría..., op. cit., p. 32.
} 
jurídica tiene, necesariamente, un componente moral y político, pero ello no implica desconocer sus peculiaridades: la unidad de la razón práctica no supone la confusión entre el Derecho, la moral y la política (...)." ${ }^{\prime 9}$

Lo explicado no es óbice para rechazar la posibilidad de construir paulatinamente un catálogo de reglas de prioridad $^{97}$ que, concebidas a través de la instrumentación de la ponderación, valgan como guías para la solución de determinados casos en que se configure una colisión de principios. ${ }^{98}$ Estas reglas reflejan la relación entre las consideraciones sobre los fundamentos que sustentan la realización plena de los principios que participan del conflicto, es decir, determinan en que supuestos el cumplimiento de un principio implica la restricción de otro; se materializan en tendencias jurisprudenciales y son parámetros de la racionalidad de la ponderación, esto en el sentido de que dotan de coherencia a la actividad decisoria de los jueces. La operatividad de estas reglas depende de la similitud sustancial de los casos reiterados en el tiempo, pues resulta obvio que un cambio de circunstancias, sean fácticas o jurídicas, puede provocar su enervación.

Como se puede apreciar, esta representación analítica se sedimenta en la aplicación misma de los principios, entendida como una necesidad ante los ineludibles déficits de un sistema normativo cerrado, integrado únicamente por reglas con autonomía semántica, es decir, por “(...) reglas cuyo significado en principio puede determinarse sin necesidad de acudir a las razones subyacentes a esas mismas reglas, a la razones que justifican modelizar deónticamente de una cierta manera una determinada forma de conducta (...) en circunstancias determinadas

\footnotetext{
96 Atienza, M., Curso..., op. cit., p. 29.

97 Vid Atienza, M., Filosofía del Derecho y transformación social, Madrid, Trotta, 2017, pp. 157-158; y Atienza, M., "A vueltas con la ponderación”, en AtienzA, M., y J.A. García Amado., Un debate sobre la ponderación, Lima-Bogotá, Palestra-Temis, 2012, pp. 34-35.

98 Apud Clérico, L., “Sobre casos y ponderación. Los modelos de Alexy y Moreso, ¿más similitudes que diferencias?, en Isonomía, no. 37, octubre de 2012, p. 130.
} 
que la regla caracteriza asimismo de manera precisa (...)." ${ }^{99} \mathrm{La}$ utilidad de los principios, sin depreciación de la función informadora que realizan en el ordenamiento jurídico, se advierte en un grupo de contingencias normativas que descartan la idoneidad de las reglas, configuradas por la imposibilidad de incluir hechos sociales con trascendencia jurídica en sus formulaciones hipotéticas, es decir, por la ocurrencia de un fallo (inevitable) de previsibilidad regulativa, o porque la selección de la regla a aplicar tiene como fuente a la arbitrariedad, o porque con la aplicación de la regla se quiebran trascendentales cánones axiológicos.

Las notas distintivas de los principios impiden una solución netamente subsuntiva ante un escenario conflictual entre ellos, ya que sus posibilidades de cumplimentación movible y condicionada $^{100}$ requieren una mayor plasticidad, capaz de expresar la materialización de su máxima realización a través de juicios ponderativos que determinen su procedencia. Evidentemente, este razonamiento no puede ser absolutizado, pues solo se refiere al plano externo del problema, lo que no desdice que entre subsunción y ponderación exista una rica relación subyacente, ya que una vez seleccionado el principio vencedor, como resultado del procedimiento ponderativo, lo que queda es subsumir el caso en sus límites de normación. En otro sentido, y en aquiescencia con Borowski, las reglas pueden hacer referencia a principios, de forma que su contenido dependa de la

99 Ruiz Manero, J., "Rule of Law y ponderación. Un límite de la ponderación y una insuficiencia de su teoría estándar," en Alonso, J. P., Imperio de la ley y ponderación de principios, Buenos Aires, Astrea, 2018, p. 25.

100 En ocasión de la diferenciación entre principios y reglas, los españoles Manuel AtienZA y Juan Ruz Manero entendieron que, en su aspecto normativo, la contribución de los principios a la argumentación es más modesta que la de las reglas, lo que fue desarrollado como la aceptación de una nota de complejidad superior de la ponderación frente a la subsunción. Para estos autores, la regla opera "(...) como un elemento que reduce la complejidad de los proceso de argumentación. Sin embargo, los principios (...) no eximen de la tarea de efectuar la ponderación (...)". Atienza, M., y J. Ruiz Manero., "Sobre principios y reglas," en Doxa, Alicante, no. 10, 1991, p. 115. Además, vid Atienza, M., y J. Ruiz Manero., Las piezas..., op. cit., pp. 21-22. 
ponderación. ${ }^{101}$ Aún más, la propia identificación del conflicto entre principios exige un razonamiento previo de subsunción, pues se hace preciso delimitar la aplicación de los principios enfrentados al caso concreto, es decir, se requiere dejar sentado que los particulares del caso se hallan incluidos en el espectro de aplicación de los principios contendientes. No obstante, es también posible que los principios en pugna cuenten con hipótesis difusas, de difícil captación, lo que implicaría realizar una subsunción valorativa, ${ }^{102}$ esto es, una estimación de los límites de la regulación principial y de las características del caso concreto a fin de lograr una apreciación de congruencia.

Subsunción y ponderación no son, ni pueden ser, operaciones antitéticas. Si bien es posible subsumir sin ponderar, es impensable poder ponderar sin subsumir. La subsunción, en un primer momento, circunscribe el espacio de la oposición de los principios, resulta una operación necesaria ex ante de la ponderación. En un segundo momento, realizada la ponderación propiamente dicha, es decir, habiéndose determinado racionalmente el principio derrotado y el principio vencedor, se requiere de la subsunción para brindar al caso concreto la solución que este último postula, siendo aquí una operación necesaria ex post de la ponderación. Existe entonces una concatenación lógica entre subsunción y ponderación que se realiza en la solución de los casos que entrañan una colisión de principios. Subsunción y ponderación tiene una relación recíproca, pues como ha indicado García Figueroa, “(...) la subsunción es

101 Cfr. Bonowski, M., "La ponderación en la estructura jerárquica del derecho", en Revista de la Fundación Manuel Giménez Abad de Estudios Parlamentarios y del Estado Autonómico, Ponencia presentada en las Jornadas sobre Los principios y la interpretación judicial de los derechos fundamentales, celebrada en el Palacio de Aljafería, sede de las Cortes de Aragón, los días 24 y 25 marzo de 2015, p. 58.

102 La expresión es utilizada por Prieto SAnchís, cuyo razonamiento al respecto consiste en explicar que a veces, las normas llamadas a ser ponderadas carecen o presenten de forma fragmentaria "(...) el supuesto de hecho, de modo que decidir que son pertinentes al caso implique un ejercicio de subsunción que pudiéramos Ilamar valorativa (...)." Prieto Sanchís, L., “El juicio de ponderación constitucional," en Carbonell, M., (editor), El principio de proporcionalidad en la interpretación constitucional, Quito, Ministerio de Justicia, 2008, p. 104. 
el ideal de la ponderación y la ponderación la realidad de la subsunción (...)."103

La incidencia de la ponderación en los predios de la estructura formal y graduada del ordenamiento jurídico, consistente en la conservación de la validez del principio derrotado, tiene como apoyatura otro de los presupuestos que han de guiar el análisis, incardinado en la afirmación de no contemplación de criterios jerárquicos en la aplicación de esta tipología normativa. La premisa que utiliza ZaGReBelsKY, resumida en reconocer que "(...) la pluralidad de principios y la ausencia de una jerarquía formal entre ellos hace que no pueda existir una ciencia sobre su articulación, sino una prudencia en su ponderación (...),"104 arroja la ratio de la peculiaridad de persistencia de la validez ya apuntada. La ponderación, consecuentemente, no versa sobre la exclusión, por declaración de invalidez, de una norma aparentemente seleccionable como criterio de resolución en un ambiente de concurrencia normativa múltiple y contradictoria ante un altercado.

En conclusión, la ponderación es un juicio de factibilidad para con la aplicación de un principio, siendo uno de sus correlatos el dejar sentado que la preferencia se desglosa de circunstancias particulares de la causa, y no en la virtualidad de premisas de jerarquía o preminencia normativa, de modo que cabe perfectamente la posibilidad de que en un caso posterior, entradas en vigor circunstancias diferenciadas, sea legítimo aplicar el principio que anteriormente fuera postergado. Es por esto que en frecuencia dicotómica se puede aseverar que los conflictos entre reglas se circunscriben al plano de la validez, mientras que los episodios de colisiones de principios la trascienden, recreándose en la dimensión (metafórica) del peso, ya que es del todo loable la admisión de que solamente los principios válidos pueden colisionar.

\footnotetext{
103 García Figueroa, A., Principios..., op. cit., p. 199.

104 Zagrebelsky, G., El derecho..., op. cit., p. 125.
} 


\section{Los principios y la teoría de los derechos fundamentales. La proporcionalidad}

La dimensión conceptual de los derechos fundamentales resulta de las más debatidas en la teoría jurídica occidental contemporánea. Como bien señaló el profesor Bernal Pulido, este concepto "(...) ha sido objeto de un sinnúmero de definiciones, acuñadas a partir de una gran variedad de perspectivas, cada una de las cuales acentúa ciertos rasgos específicos o enfatiza determinados matices o singularidades de esta figura jurídica (...).”105

Ahora bien, la teoría de los derechos fundamentales desarrollada durante el último cuarto del siglo $\mathrm{XX}$, que resulta ser la salida teórica más exhaustiva y extendida, no puede explicarse sin alusión a la teoría de los principios, y muy especialmente a la variante descrita por Robert AlEXy. En este sentido, la divergencia conceptual que opera entre los principios y las reglas ha fungido como apoyatura de cuestiones tan esenciales como la identificación del contenido y de los límites de los derechos fundamentales; además de posibilitar la concepción, con base en la experiencia jurisdiccional, de la potencialidad conflictual que estos presentan en ocasión del tráfico jurídico, en tanto sus contenidos colisionan en no pocos conflictos concretos que trascienden a la mera aplicación por subsunción de una regla.

Es en esta cadencia que Alexy ha sostenido que la distinción entre principios y reglas constituye "(...) la base de la fundamentación iusfundamental y es una clave para la solución de problemas centrales de la dogmática de los derechos fundamentales. Sin ella, no puede existir una teoría adecuada de los límites, ni una teoría satisfactoria de la colisión y tampoco una teoría suficiente acerca del papel que juegan los derechos fundamentales en el sistema jurídico (...)." ${ }^{106}$ Es decir, esta distinción se presenta, además, como "(...) un soporte sobre el que se asienta, en

105 Bernal Pulido, C., El principio...., op. cit., p. 100.

106 Alexy, R., Teoría de los derechos..., op. cit., p. 81. 
general, la solución de todos los casos en los que se encuentran en juego los derechos fundamentales (...)." ${ }^{107}$

La expresión regular de la teoría de los derechos fundamentales en derredor del principalismo, que como se dijo ostenta su epicentro en la iusfilosofía alexyana, tiene su base en la concepción de los derechos constitucionales como principios, y de estos como mandatos de optimización que ordenan que algo debe realizarse en la mayor medida posible de acuerdo con las posibilidades fácticas y normativas que concurran en la figuración de un supuesto concreto. Así, los conflictos entre derechos fundamentales se resuelven mediante la realización de un test de proporcionalidad, entendido este como el principio de mayor relevancia $a b$ intra del ordenamiento jurídico. Este principio de proporcionalidad se estructura de forma tripartita, es decir, contempla en su ontología tres subprincipios: el de idoneidad, el de necesidad y el de proporcionalidad en sentido estricto o ponderación.

Los subprincipios de idoneidad y de necesidad hacen referencia a la optimización en relación con las posibilidades fácticas, ya que de lo que se trata es de “(...) impedir ciertas intervenciones en los derechos fundamentales, que sean evitables sin costo para otros principios (...)" ${ }^{108}$ Esto se traduce en que la imposición de una medida que limita el ejercicio de un derecho en aras de satisfacer otro, debe ser la más idónea y necesaria, dentro de todas las opciones posibles, en aras de realizar esta finalidad, es decir, no puede configurarse otra medida que suponga la consecución de fines idénticos y que implique un resultado limitativo de menor entidad. Por otra parte, el subprincipio de proporcionalidad en sentido estricto o ponderación se refiere a la optimización en relación con las posibilidades normativas, estando dotado de una estructura

\footnotetext{
107 Cianciardo, J., "Principios...," op. cit., p. 894.

108 AlEXY, R., Teoría de la argumentación jurídica. La teoría del discurso racional como teoría de la fundamentación jurídica, Lima, Palestra, 2007, p. 459.
} 
también tripartita: la ley de la ponderación, la fórmula del peso y las cargas de la argumentación.

La ley de la ponderación es anunciada a través de una proposición que establece que “(...) cuando mayor sea el grado de no satisfacción o restricción de uno de los principios, tanto mayor deberá ser el grado de la importancia de la satisfacción del otro (...)." ${ }^{109}$ De esta manera se expresa que la optimización en relación con los principios que juegan en sentido contrario no consiste en nada diferente a la ponderación. El desarrollo de esta ley consta de tres pasos fundamentales, a saber, la definición del grado de la no satisfacción o de afectación de uno de los principios; la definición de la importancia de la satisfacción del principio que juega en sentido contrario; y la definición de si la importancia de la satisfacción del principio contrario justifica la restricción o la no satisfacción del otro. ${ }^{110}$

109 Idem, p. 460.

110 Ibidem, p. 460. Para mostrar la posibilidad de juicios racionales en relación con la intensidad de la interferencia y con los grados de importancia, AleXY analiza dos decisiones del Tribunal Constitucional Federal alemán: 1-) El primer supuesto decisorio se relaciona con las advertencias de los riesgos para la salud. AleXY describe las circunstancias del caso del modo que sigue: “(...) El Tribunal califica el deber de las compañías de tabaco de advertir sobre el riesgo de fumar como una interferencia relativamente menor o leve respecto a la libertad de ejercer una profesión (Berufsausübungsfreiheit). Por lo contrario, una prohibición total de todos los productos del tabaco sería considerada una interferencia grave. Entre estos casos leves y graves se pueden encontrar interferencias de intensidad moderada. En este sentido, es posible desarrollar una escala con niveles de leve, moderado y grave. Este ejemplo demuestra que se pueden realizar asignaciones válidas de acuerdo con esta escala (...)." Ello también es posible, sigue explicando AlEXY, "(...) en relación con la fundamentación opuesta. Los riesgos que se generan por fumar son enormes. Por ello, las razones que justifican la interferencia son de gran peso, En este sentido, si la intensidad de la interferencia se establece como leve o menor, y el grado de importancia de las razones para interferir es alto, entonces, el resultado del examen de proporcionalidad en el sentido estricto puede ser bien descrito -como, de hecho, lo hizo el Tribunal Constitucional Federal alemán- como obvio (...)." AleXY, R., "Ponderación, control de constitucionalidad y representación," en IBÁÑEZ, P. A., y AlEXY, R., Jueces..., op. cit., p. 5-6; 2-) El segundo supuesto versa sobre la clásica colisión entre la libertad de expresión y el derecho al honor. Alexy describe las circunstancias del caso del modo que sigue: "(...) Una revista satírica de gran circulación, Titanic, se refirió a una militar parapléjico retirado como asesino nato y, en una edición posterior, le llamó tullido. Un tribunal alemán (el Tribunal Superior de Düsseldorf) resolvió en contra de la revista, condenándola a 
La fórmula del peso, por su parte, desarrolla la ley de la ponderación, esto en el sentido de determinar el peso abstracto y el peso concreto de los principios que colisionan y la intensidad en abstracto y en concreto de la restricción de los derechos del afectado de modo de no exigirle, además, tolerar una restricción insoportable. ${ }^{111}$ Esta fórmula es presentada por Alexy en términos aritméticos, y constituye, expresado sintéticamente un procedimiento para determinar el peso concreto del principio Pi en relación con el principio $\mathbf{P j}$, a la luz de las circunstancias de un caso. ${ }^{112}$

Finalmente, las decisiones o proposiciones conectadas por la fórmula del peso deben ser justificadas mediante ulteriores argumentos. En otras palabras, “(...) la fórmula del peso es una clase de argumento. Las formas de argumento definen la estructura lógica de movimientos dentro de los discursos y muestran cómo los movimientos se relacionan entre sí (...)."113

pagar al oficial daños y perjuicios por un monto de 12 mil DM. Titanic interpuso un recurso de constitucionalidad. El Tribunal Constitucional Federal llevó a cabo una ponderación de caso específico entre la libertad de expresión de la revista (artículo 5 (1) (1) de la norma fundamental) y, el derecho general a la identidad personal del oficial (artículo 2 (1) en conexión con el artículo 1 (1) de la misma norma) (...)." Para tal fin, explica AleXY, el Tribunal determinó la intensidad de la afectación de esos derechos y las puso en relación. En el primer caso, relativo a la construcción asesino nato, se considera que la condena de la revista a indemnizar es una limitación grave de la libertad de expresión, mientras que la afectación del derecho al honor tendría como máximo una afectación de grado medio, por tratarse de una sátira y ser una fórmula empleada también en otras ocasiones y con otros personajes. Así que, comparadas ambas magnitudes, el Tribunal Constitucional Federal habría comprobado que la condena de Titanic resultaba desproporcionada. En lo referido a la segunda expresión cuestionada, es decir, tullido, el Tribunal habría comprobado que se trata de una vulneración muy grave o extraordinariamente grave del derecho al honor, pues es expresión humillante y que manifiesta falta de respeto. Así que, en este caso, la grave intervención en la libertad de expresión que supone la condena a indemnizar está compensada por la gravedad por lo menos idéntica del atentado contra el derecho al honor. AleXY, R., "Ponderación...," op. cit., pp. 6-7; y AleXY, R., Epílogo..., op. cit., pp. 34-35.

111 Apud Clérico, L., El examen..., op. cit., pp. 354 y ss.

112 Cfr. Alexy, R., "La fórmula del peso," en Carbonell, M., (editor), El principio..., op. cit., pp. 13-42. Una explicación de la cuestión en Bernal Pulido, C., "La racionalidad de la ponderación," en CarbonelL, M., (editor), El principio.... op. cit., pp. 43-68.

113 Alexy, R., “Ponderación...," op. cit., p. 10. 
En definitiva, la ponderación no es posible sin el discurso, "(...) y las distintas clases de argumentos o estructuras de inferencias incluyen necesariamente la estructura ponderativa, tal y como lo pone de manifiesto la fórmula del peso (...)."114

\section{Precisión conclusiva}

Es posible concluir que en el desarrollo de la reflexión jurídica occidental enmarcada en el siglo XX, las alusiones principalistas han sido constantes y han asumido derroteros de análisis diferenciados. En sentido general, las teorías principalistas (o sobre los principios) han tenido como denominador común la negación de las conclusiones del positivismo jurídico. Así, las teorías sobre los principios se han vinculado con conclusiones más generales relativas a la ontología del Derecho, específicamente en derredor de la aceptación o la negación de la tesis de separación entre el Derecho y la moral.

Consonantemente, las teorías sobre los principios han redimensionado los estudios sobre las normas jurídicas, esto por introducir en el debate la posibilidad de establecer distinciones entre reglas y principios, tanto en un sentido débil como en un sentido fuerte, basadas en la concurrencia de características divergentes en lo relativo a las dimensiones de estos tipos normativos (dimensión de validez en las reglas y dimensión de peso en los principios) y en la metodología de su aplicación (de todo o nada en las reglas y como mandatos de optimización en los principios).

Más recientemente, las teorías sobre los principios han tenido un impacto notable en los estudios sobre los derechos fundamentales, en el sentido de asumirse los primeros como las normas que contienen a los segundos, lo que ha permitido conjugar una visión más dinámica del contenido y los límites de estos, conjugándose en este sentido el principio de proporcionalidad como un instrumento clave para la función jurisdiccional.

114 Alexy, R., “Ponderación...," op. cit., pp. 10-11. 
Igualmente, el principalismo ha tenido como dos de sus correlatos fundamentales a la configuración de la ponderación como método de aplicación del Derecho que, diferenciado de la subsunción, atiende fundamentalmente a la dimensión de peso de los principios, y a una concepción de la argumentación jurídica como una de sus exigencias elementales en el contexto del Estado constitucional de Derecho. 